\title{
BEHAVIOUR PROBLEMS OF CATS REARED INDIVIDUALLY OR IN COEXISTENCE WITH OTHER ANIMALS (CATS, DOG)
}

\author{
Kmecová, N. ${ }^{1}$, Weissová, T. ${ }^{2}$, Vdoviaková, K. ${ }^{3}$ \\ ${ }^{1}$ Institute of applied ethology and professional ethics \\ ${ }^{2}$ Small animal clinic \\ ${ }^{3}$ Department of Anatomy, Histology and Physiology \\ University of Veterinary Medicine and Pharmacy \\ Komenského 73, 04181 Košice \\ The Slovak Republic
}

noemakmecova@gmail.com

\begin{abstract}
The aim of this study was to determine whether behaviour problems in indoor cats depend on the number of cats in a household or rearing one or more cats in a household together with a dog. The study was carried out on animals which were divided for the purpose of this study into 4 groups: (1) households with one cat; (2) households with two cats; (3) households with three or more cats; (4) households with one or more cats and a dog. Altogether 91 cats were included in the study. The practical part of this investigation was based on a questionnaire. It was observed that the probability of behaviour problems was not related unambiguously to the number of cats in a household or the company of a dog. The percentage of the occurrence of changed behaviour did not differ significantly between the groups.
\end{abstract}

Key words: behaviour problems; cat; dog; individual and group rearing

\section{INTRODUCTION}

Although Queen Victoria popularized cats as domestic animals, it has been only lately that cats have begun to adjust to indoor-only conditions. The fact is, that today cats are the most frequent pets found in American households. According to the Humane Society of the USA, there are 83.3 million dogs and 95.6 million cats kept as household pets in the country [7]. The increased population of humans living in cities and towns is probably one of the main reasons for the increasing popularity of cats. Cats are better equipped for life in a smaller space, require less care and can coexist easier with humans in these hectic times.

Cat owners who try to adjust cats to their own lifestyle without considering the essence of existence of these animals and their needs, eventually find out that they have at home an unhappy cat which behaves in the way considered inappropriate by the owner. The social behaviour of cats is closely related to behaviour problems of these animals. The cat owners should try to understand how domestication has affected the behaviour of these animals. Each cat has its 
own specific story, a repertoire of experiences which affect its own perception of the world. First we have to understand cats in general before we can comprehend the laws according to which the individual cats will act and behave [7].

One of the reasons for keeping cats exclusively indoors is the fact that owners try to prevent conflicts which may develop when a new cat tries to integrate into the territory in the garden of its owner which already belongs to a neighbour's cat. On the other hand, if the cat has to stay throughout its life in the relatively small space of our households, this can induce stress without the presence of another animal. However, although people have kept cats in apartments for more than 30 years, only a few systemic studies have been conducted with the aim of revealing whether cats consider such "prisons" as stressful [5].

Barry and Crowell-Davis [3] described the relationship of two castrated indoor cats in their study which focused on differences in the behaviour within genders. They observed that there were no significant differences between genders in friendly and aggressive behaviour. However, in households with two females, no mutual cleaning of cats was observed, but in the case of households with two tomcats the animals spent more time in close proximity [3].

Consequently, the life of an indoor cat is considerably affected by its owner as it was indicated by Adamelli et al. [1] who investigated the cat - man relationship with respect to their quality of life in a group of 62 cats. The quality was evaluated by means of a questionnaire which focused on the care of the animal, its behaviour, characteristic features of the owner and his/her cat, simple physical examination of cat and Lexington's test of pet attachment. This test revealed a medium quality of life of $87.2 \%$ of the cats. Although the quality of life of these cats was good and they were in good physical condition, only $16.1 \%$ showed no abnormal behaviour. Scientists who performed this study concluded that the quality of a cat's life is affected considerably by coexistence with other animals. All analysed aspects (care, behaviour, physical condition) were eventually affected by the owners. Other characteristics (gonadectomy, age at obtaining the animal, coexistence with other cats) which affected the animals to a lesser but still significant extent, were determined by performed testing [1].

In order to understand the behaviour of cats, particularly with the aim of finding out more about their ability to coexist with other cats, dogs or people, one should first gain an understanding of the development of their social behaviour in the process of domestication of a solitary wild cat compared to the domestic cat, the animal we know today.

The aim of this study was to determine whether behaviour problems and inappropriate behaviour of indoor cats depends on the number of cats in the household or their coexistence with a dog, by means of a questionnaire.

\section{MATERIALS AND METHODS}

The subject of this investigation involved indoor cats divided for the purpose of this study into the following 4 groups: (1) households with one cat $(n=10)$; (2) households with two cats $(n=7)$; (3) households with three or more cats $(n=11)$; and (4) households with one or more cats living under one roof with a dog $(n=5)$. Altogether 91 cats were involved in the study. All of them were cats kept exclusively indoors without the possibility of free movement outside. This eliminated the influence of the external environment on their behaviour which the owner normally is unable to observe. The households/breeding units were selected at random.

The practical part of the study was based on a questionnaire. Also we selected written and electronic approaches in order to obtain additional relevant data.

The questionnaire started with questions seeking information about the owner of the animal(s) and the animal(s) themselves. The questions were divided to the following groups: Cat owner; Relationship with household members; Health state; Environment; Daily activities; Observed behavioural changes. If any question was not clearly answered or the answer was incomplete or too brief, we sent supplemental questions to the responders that helped to elucidate aspects concerning the behaviour of cat(s). The respondents were also asked to provide a scheme of his/her apartment/ house which constituted the territory of the cat(s), together with a description where the cat(s) exhibited various forms of the behaviour of interest.

\section{RESULTS}

The information obtained through questionnaires was processed and is summarised in Tables 1 and 2 . 
Table 1. Percentage evaluation of results

\begin{tabular}{|c|c|c|c|c|}
\hline & \multicolumn{2}{|c|}{ Behaviour problems } & \multirow{2}{*}{$\begin{array}{l}\text { Unsuitable toileting } \\
\text { behaviour associated } \\
\text { with organ disease }\end{array}$} & \multirow[b]{2}{*}{$\begin{array}{l}\text { Cat }- \text { dog } \\
\text { relationship }\end{array}$} \\
\hline & $\begin{array}{c}\text { Aggression to man, cats; } \\
\text { marking; other }\end{array}$ & $\begin{array}{l}\text { Territorial /maternal } \\
\text { aggression; marking }\end{array}$ & & \\
\hline $\begin{array}{l}\text { Group } 1 \\
\text { (one cat) }\end{array}$ & $40 \%$ & $\begin{array}{c}40 \% \text {, of that } 20 \% \text { involved } \\
\text { single occurrence }\end{array}$ & - & - \\
\hline $\begin{array}{l}\text { Group } 2 \\
\text { (two cats) }\end{array}$ & $43 \%$ & $29 \%$ & - & - \\
\hline $\begin{array}{l}\text { Group } 3 \\
\text { (3 and more cats) }\end{array}$ & $55 \%$ & $45 \%$ & $27 \%$ & - \\
\hline $\begin{array}{l}\text { Group } 4 \\
\text { (cat/cats + dog) }\end{array}$ & $20 \%$ & $20 \%$ & - & $\begin{array}{l}100 \% \text { neutral } \\
\text { to positive }\end{array}$ \\
\hline
\end{tabular}

Table 2. Descriptive evaluation of results

\begin{tabular}{|c|c|c|c|}
\hline & $\begin{array}{c}\text { Aggression to man, cats; } \\
\text { other }\end{array}$ & $\begin{array}{l}\text { Territorial/maternal } \\
\text { aggression; marking; other }\end{array}$ & $\begin{array}{l}\text { Unsuitable toileting behaviour } \\
\text { associated with organ disease }\end{array}$ \\
\hline $\begin{array}{l}\text { Group } 1 \\
\text { (one cat) }\end{array}$ & Aggression to man; vocalisation & $\begin{array}{l}\text { Territorial aggression; } \\
\text { single display of territorial aggression; } \\
\text { urine-marking (bed) }\end{array}$ & - \\
\hline $\begin{array}{l}\text { Group } 2 \\
\text { (two cats) }\end{array}$ & $\begin{array}{l}\text { Aggression to man and cats; } \\
\text { urine-marking }\end{array}$ & $\begin{array}{c}\text { Territorial aggression; marking and } \\
\text { vocalisation in oestrus }\end{array}$ & - \\
\hline $\begin{array}{l}\text { Group } 3 \\
\text { (3 and more cats) }\end{array}$ & $\begin{array}{l}\text { Aggression to man and among cats; } \\
\text { elimination disorders, fear; pica }\end{array}$ & $\begin{array}{l}\text { Territorial aggression; aggression and } \\
\text { marking in oestrus; maternal aggres- } \\
\text { sion }\end{array}$ & Diabetes mellitus and FLUDT \\
\hline $\begin{array}{l}\text { Group } 4 \\
\text { (cat/cats + dog) }\end{array}$ & Petting aggression to man & Territorial aggression & - \\
\hline
\end{tabular}

FLUDT — feline lower urinary tract disease

\section{DISCUSSION}

Bradshaw [4] in his most relevant book titled "Cat sense", stated that domestication not only suppressed the internal distrust of people in wild cats, but also reduced their alertness toward other cats. According to this author, the social behaviour of cats probably began to develop when they discovered food storages by means of which humans made the concentrated food sources available to cats. Each cat which maintained natural distances from all members of its own species, was not able to utilize these new sources as effectively as cats capable of recognising the mutual relations and use them for their own benefit. Another advantage involved the rearing of the young. Two and more cats which gathered their kittens were able to take care of them much better than isolated cats which had to leave their young when they went to hunt. Life in a family also provides the cats the opportunity to learn one from another which is more advantageous than learning individually.

The first group evaluated in our study included households with one cat. In this group both aggression to man and cats (40\%) and territorial aggression (40\%) were observed. Although the proportion of animals with aggression to man and cats in this group was lower in comparison with groups two and three of cats, this cannot be considered proof that cats reared alone, i.e. without the presence of a feline "rival", will not display problem behaviour which is in agreement with the observations by Bradshaw [4]. 
The occurrence of behaviour problems (43\% and 29\%), detected in households with two cats in our study can again support the correctness of other conclusions made by Bradshaw [4] and of additional studies mentioned in this section. However, behavioural problems in the form of aggression were observed also in unrelated cats (two intact and two spayed) and in two related male cats. Unsuitable behaviour was associated with manifestation of oestrus in cats and therefore we consider behaviour problems a more important indicator of the relationship between two cats.

According to Bradshaw [4], the fact that two cats have the same owner does not necessarily mean that they will get along well with one another. Many cats observe the principal rule of cat society, namely to proceed cautiously when approaching any cat which is not part of the family. However, the majority of owners are ignorant of this rule and carelessly obtains another cat in belief that these two animals will soon become good friends. Although this may apply in general to dogs, the cats will more likely only tolerate each other [4].

Cat societies are matriarchal and are not so strongly developed as those of dogs. Each social unit begins with one female and its progeny and if there is abundance of food, daughters will stay with their mother even after having their own young and cats will share the care of them. A typical small colony consists of a mother and her adult daughters with their last litters and one or two tomcats. Any important situation, such as the death of the dominant female, may result in disturbed relationships between some cats, increases the incidence of aggressive behaviour and may lead to division of the colony into two or more smaller groups.

Information about relations between related cats in colonies and the unrelated ones presented by Bradshaw [4] are also useful for the evaluation of our results. Their practical validity is confirmed by our results obtained in the group with three or more cats, where the occurrence of behaviour problems was the highest (55\% and $45 \%$ ). In agreement with the above author, in one household with six cats which were unrelated (with the exception of one pair) and were brought together at different times from different conditions the parallel occurrence of aggression to man and cats and territorial and maternal aggression was the highest. Differences related to increasing number of cats (from 3 up to 12) were also evident. We observed higher occurrence of undesirable urination associated either with behaviour problem or oestrus when six or more cats were kept together.

The common denominator of breeding centres with higher number of cats was unsuitable but understandably also natural behaviour associated with the reproduction cycle and artificial making of cat societies which included the following: sexual aggression of breeding males and females, unwanted elimination in the form of marking in oestrus and maternal aggression related to protection of the litter.

Feuerstein and Terkel [6] investigated the relationship of cats and dogs living together under the same roof. This study was based on a questionnaire and the direct observation of the animals. The results revealed that both species were capable of developing relatively friendly relationship with another species and the gender had only a little effect on the character of this relationship. Also, adopting the cat before the adoption of a dog contributes to the development of a basis for a friendly relationship provided that their first contact takes place at a young age (cat up to 6 months of age, and a dog up to one year). According to these authors it is possible to conclude that the mutual exposure of one species to another at an early age facilitates the mutual recognition of body language by these animals and the subsequent development of a friendly relationship [6].

The results of Feuerstein and Terkel [6], as well as ours, disprove the opinion that a cat and a dog in one household cannot get along well with each other. In all households in group 4, the relationship of cat and dog was either neutral or positive and owners observed that the animals were involved in a hunting imitation play. As far as problem behaviour was concerned, only in $20 \%$ of households the owners observed aggression to cats which were brought to the household for a short time only. This is however understandable behaviour of the indoor cat which coexists in one room apartment with two owners and a dog. Additional behaviour problems were observed in $20 \%$ of the households in the form of petting aggression.

When a new cat was brought to the household, changed behaviour in the form of aggression was observed in $43 \%$ of animals from group 2, which lasted from two days up to one week, and in $45 \%$ of cats from group 3 associated with undesirable urination which lasted two to three days, either in resident or newly introduced cats. Our results resemble those of Levine et al. [8] who reported that introducing another cat into a household with several other cats, result- 
ed in displays of aggressive behaviour in about half of them manifested by scratching and biting.

The study by A mat et al. [2], dealing with main risk factors associated with behaviour problems in animals, showed that $47 \%$ of owners of 336 cats who visited the veterinary clinic because of behaviour problems, complained about aggressive behaviour and 39\% reported undesirable elimination. Of all aggressive conflicts, $64 \%$ involved aggressive behaviour against cats and $36 \%$ were conflicts with man, most frequently with owners. The most frequent forms of aggression to man were play aggression and stroking aggression. The majority of problems with elimination included urination (59\%), urination and defecation (32\%) and defecation alone (9\%), and the most frequent reason was toilet aversion (63.4\%). Indoor cats exhibited more behaviour problems than cats with access to the exterior and the aggressiveness occurred more frequently in households with one cat [2]. Our results agree with the observations of the above authors [2] with one exception, namely that the object of aggression to man were toward the owners. According to our results, the owners was a target of such behaviour in only three out of seven cases.

The summary of the detected behaviour problems indicates that the most frequent behavioural problem in all groups was aggression to man or other cats and inappropriate toileting behaviour rated as second. Less frequent or rare problems were vocalisation, pica (sucking microtene bags) and fear.

\section{CONCLUSIONS}

On the basis of our results, we can conclude that the probability of the occurrence of behaviour problems was not related unambiguously to the number of cats in a household (breeding centre) nor to its coexistence with a dog. The percentage of occurrence of changed behaviour following the introduction of a new cat did not differ markedly between the groups.

\section{REFERENCES}

1. Adamelli, S., Marinelli, L., Normando, S., Bono, G., 2005: Owner and cat features influence the quality of life of the cat. Appl. Anim. Behav. Sci., 94, 89-98.

2. Amat, M., Luis, R. J. T., Fatgo, J. et al., 2009: Potential risk factors associated with feline behaviour problems. Appl. Anim. Behav. Sci., 121, 134-139.

3. Barry, K. J., Crowell-Davis, S. L., 1999: Gender differences in the social behaviour of the neutered indoor-only domestic cat. Appl. Anim. Behav. Sci., 64, 193-211.

4. Bradshaw, J., 2014: Cats together. In Cat Sense: The Feline Enigma Revealed. Penguin books, 161-190.

5. Bradshaw, J., 2014: Cats and their people. In Cat Sense: The Feline Enigma Revealed. Penguin books, 214 pp.

6. Feuerstein, N., Terkel, J., 2008: Interrelationships of dogs (Canis familiaris) and cats (Felis catus L.) living under the same roof. Appl. Anim. Behav. Sci., 113, 150-165.

7. Galaxy, J., Benjamin, K., 2014: The move indoors. In Catification. A Penguin Random House Company, New York, 14 - 15.

8. Levine, E., Perry, P., Scarlett, J. et al., 2005: Intercat aggression in households following the introduction of a new cat. Appl. Anim. Behav. Sci., 90, 325-336.

Selected paper from the 59th STUDENT SCIENTIFIC CONFERENCE, Section II - Clinical section, held at the University of Veterinary Medicine and Pharmacy in Košice, SR, on April 6, 2016. 